\title{
Electrophoretically Deposited Multiwall Carbon Nanotubes (MWCNTS) and Hydroxyapatite (HA) on Stainless Steel (SS): Effective Biomaterial for Orthopedic Implant Applications
}

Sharif Hussein Sharif Zein* and Muhammad Faiq Abdullah

School of Chemical Engineering, Engineering Campus, Universiti Sains Malaysia, Malaysia

Since many decades, metals and alloys are widely used in substitution for anatomical structures due to their extraordinary mechanical properties. Stainless steel (SS), cobalt-chromium (Co-Cr) alloys and titanium (Ti) and its alloys are among the metals known to be used in orthopedic implant devices [1,2]. Among these, type 316L SS is widely employed for implantation purposes in orthopedic surgery due to its corrosion resistance, cost effective and superior mechanical properties [3]. However, the uncoated SS is susceptible to corrosion due to chemical and electrochemical degradation at some finite rate [1] which leading to the reduction of the ultimate strength of SS and possibly caused mechanical failure of implant and may impose revision surgery [4]. This limitation could be minimized if the SS is able to be coated with multiwall carbon nanotubes (MWCNTs) and hydroxyapatite (HA).

$\mathrm{HA}$ is one of the major constituents in bone and teeth as it's bioactive and biocompatibility behavior enabled it to interact with surrounding bone. However, HA have poor mechanical properties as it has limitation in forming into complex shapes with control microstructures [3,5-7]. MWCNTs are attractive for biomedical applications especially for developing nanofibrous bioactive surfaces with HA for its extraordinary high mechanical strength and nano-scale morphology [8-11]. The mechanical reinforcement of HA layers could be obtained using different types of MWCNTs (pristine MWCNT and functionalized MWCNT) to achieve good dispersion of MWCNTs in ceramic matrix and to induce the ideal interface between MWCNTs and HA [8]. Electrophoretic deposition (EPD) is proposed as the attractive and promising technique for production of unique microstructures and nanostructures with complex materials combination. In this work, MWCNTs and HA layers are deposited on SS using EPD and was proposed to be used as the anatomical substitution in orthopedic implant. EPD is a simple electrochemical process that widely been used for polymers coating $[8,12-15]$. This technique is gaining intense interests for the production of novel coatings or films of MWCNTs on conductive substrate due to its simplicity, cost effective (not involved any complex procedure or reaction), versatility to be applied for different materials and combination of materials, and required only basic equipment with the ability to scale-up to large product volume and sizes $[16,17]$. In addition, EPD has the ability to produce uniform deposits with high microstructural homogeneity, provide adequate control of deposit thickness, and deposit coatings on wide range of shapes, 3D complex and porous structure [13,15-17].

Despite its huge potential in production of microstructures coatings or films, more experiments and theoretical studies need to be done to fully understanding the mechanism of EPD. Most of the previous studies of EPD were conducted using unsatisfactory and time consuming trial and error approaches due to lack of availability relationship that linked the parameters of EPD with final deposit properties [15]. EPD used electrophoresis mechanism to move the charged particles in suspension by applying an electric field to deposit them in an ordered manner on a substrate to coat thin and thick film $[16,18]$. Key factor to achieve successful deposition of materials using EPD is to produce a stable suspension with low ionic conductivity in which the particles have high zeta potential $[17,19,20]$. Zeta potential relates to particles double's layer thickness which affects the particle agglomeration and stability of suspension. When zeta potential value is zero, surface charge is also zero and electrostatic interaction at this point would be minimize and caused the suspension particles tend to agglomerate. Water has been considered as the suitable solvent for suspension preparation due to its advantages in cost and environmental friendly compared to organic solvent [17]. Furthermore, water possess higher dielectric constant which leading to higher electrophoretic mobility and zeta potential [21]. Figure 1(a) shows the electrophoretically deposited of functionalized MWCNTs of MWCNT-OH on type 316L SS, followed by deposition of HA on coating layer of MWCNT-OH as shown in Figure 1(b). The
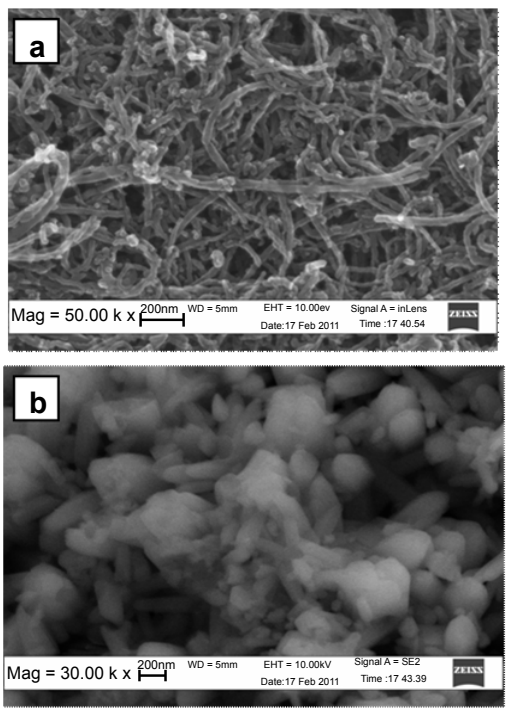

Figure 1: High magnification field emission gun scanning electron microscopy images of (a) MWCNT- OH coating on SS and (b) HA coating on SS/MWCNT$\mathrm{OH}$.

${ }^{*}$ Corresponding author: Sharif Hussein Sharif Zein, School of Chemical Engineering, Engineering Campus, Universiti Sains Malaysia, Seri Ampangan, 14300 Nibong Tebal, Seberang Perai Selatan, Pulau Pinang, Malaysia, Tel: 604-599-6442; E-mail: chhussein@eng.usm.my

Received February 27, 2012; Accepted February 27, 2012; Published February 29, 2012

Citation: Zein SHS, Abdullah MF (2012) Electrophoretically Deposited Multiwal Carbon Nanotubes (MWCNTS) and Hydroxyapatite (HA) on Stainless Steel (SS): Effective Biomaterial for Orthopedic Implant Applications. J Bioengineer \& Biomedical Sci 2:e103. doi:10.4172/2155-9538.1000e103

Copyright: @ 2012 Zein SHS, et al. This is an open-access article distributed under the terms of the Creative Commons Attribution License, which permits unrestricted use, distribution, and reproduction in any medium, provided the original author and source are credited. 
Citation: Zein SHS, Abdullah MF (2012) Electrophoretically Deposited Multiwall Carbon Nanotubes (MWCNTS) and Hydroxyapatite (HA) on Stainless Steel (SS): Effective Biomaterial for Orthopedic Implant Applications. J Bioengineer \& Biomedical Sci 2:e103. doi:10.4172/21559538.1000e103

Page 2 of 2

surface oxides on the MWCNT-OH could electrostatically stabilize the aqueous suspension for certain period of times as reported by Thomas et al. [22]. The functionalization process could reduce the MWCNT length which minimizing the aggregates present in suspension. The homogeneity of MWCNT-OH coating layer on SS in 2D orientation could be appreciated with no micro-cracks observed by inspection at different magnification after it went through drying process. However, voids and pits could be observed on surface of HA coating layer due to high voltage used [23]. HA suspension precipitated and settles down very fast before HA particles could deposit on the substrate, whereas high voltage used in order to overcome this limitation. High voltage promoted the formation of hydrogen evolution via electrolysis of water [17] which increased the porosity of coating [23] and resulted in inhomogeneous deposition of HA. Lower voltage could be used to prevent hydrogen evolution if the stability of HA suspension could be increased.

An effective biomaterial that ideal as bone replacement should possess the biocompatible, bioactive, osteoconductivity [24], superior mechanical properties $[8,23,25]$ and excellent corrosion resistance. So, is it the type 316L SS coated with MWCNTs and HA is the answer for future material to be used in orthopedic implant? While the deposition of MWCNTs and HA have indeed met the required characteristics and properties of the ideal bone replacement material, more in vitro and in vivo tests in appropriate simulation of human environment need to be performed in order to investigate the corrosion behavior of SS coated with MWCNTs and HA before it could be accepted to replace the current used of type 316L SS [2]. Therefore, the corrosion behavior of MWCNTs and HA layers deposited on SS is proposed to be investigated using in vitro electrochemical techniques, which included electrochemical impedance spectroscopy (EIS) and potentiodynamic polarization curve studies $[3,26]$ to determine the acceptability of modified SS to be used in orthopedic implant devices.

\section{References}

1. Kamachimudali UK, Sridhar TM, Raj B (2003) Corrosion of bio implants Sadhana-Academy Proceedings in Engineering Sciences 28: 601-637.

2. Sivakumar M, Mudali U, Rajeswari S (1994) In vitro electrochemical investigations of advanced stainless steels for applications as orthopaedic implants. J Mater Eng Perform 3: 744-753.

3. Sridhar TM, Kamachi Mudali U, Subbaiyan M (2003) Preparation and characterisation of electrophoretically deposited hydroxyapatite coatings on type 316L stainless steel. Corros Sci 237-252.

4. Jacobs JJ, Gilbert JL, Urban RM (1998) Corrosion of metal orthopaedic implants. J Bone Joint Surg Am 80: 268-282.

5. Hench LL (1991) Bioceramics: From Concept to Clinic. J Am Ceram Soc 74 1487-1510.

6. Jevtic M, Mitric M, Skapin S, Jancar B, Ignjatovic N, et al. (2008) Crystal Structure of Hydroxyapatite Nanorods Synthesized by Sonochemical Homogeneous Precipitation. Cryst Growth Des 8: 2217-2222.

7. Lu H, Qu Z, Zhou Y (1998) Preparation and mechanical properties of dense polycrystalline hydroxyapatite through freeze-drying. J Mater Sci Mater Med 9: 583-587.

8. Boccaccini AR, Keim S, Ma R, Li Y, Zhitomirsky I (2010) Electrophoretic deposition of biomaterials. J R Soc Interface 7 Suppl 5: S581-613.

9. Cho J, Konopka K, Rozniatowski K, García-Lecina E, Shaffer MSP, et al. (2009) Characterisation of carbon nanotube films deposited by electrophoretic deposition. Carbon 47: 58-67.

10. Grandfield K, Sun F, Fitzpatrick M, Cheong M, Zhitomirsky I (2009) Electrophoretic deposition of polymer-carbon nanotube-hydroxyapatite composites. Surf Coat Technol 203: 1481-1487.

11. Wang L, Chen Y, Chen T, Que W, Sun Z (2007) Optimization of field emission properties of carbon nanotubes cathodes by electrophoretic deposition. Mater Lett 61: 1265-1269.

12. Bai Y, Neupane, MP, Park IS, Lee MH, Bae TS, et al. (2010) Electrophoretic deposition of carbon nanotubes-hydroxyapatite nanocomposites on titanium substrate. Mater Sci Eng, C 30: 1043-1049.

13. Boccaccini AR, Cho J, Roether JA, Thomas BJC, Jane Minay E, et al. (2006) Electrophoretic deposition of carbon nanotubes. Carbon 44: 3149-3160.

14. Boccaccini AR, Cho J, Subhani T, Kaya C, Kaya F (2009) Electrophoretic deposition of carbon nanotube-ceramic nanocomposites. J Eur Ceram Soc 30: 1115-1129.

15. Corni I, Ryan MP, Boccaccini AR (2008) Electrophoretic deposition: From traditional ceramics to nanotechnology. J Eur Ceram Soc 28: 1353-1367.

16. Sarkar P, Nicholson PS (1996) Electrophoretic deposition (EPD): mechanisms, kinetics, and application to ceramics. J Am Ceram Soc 79: 1987-2002.

17. Van der Biest OO, Vandeperre L J (1999) Electrophoretic deposition of materials. Annu Rev Mater Sci 29: 327-352.

18. Jensen ON, Larsen MR, Roepstorff P (1998) Mass spectrometric identification and microcharacterization of proteins from electrophoretic gels: strategies and applications. Proteins 2: 74-89.

19. Zhitomirsky I (2000) Electrophoretic hydroxyapatite coatings and fibers. Mater Lett 42: 262-271.

20. Zhitomirsky I (2002) Cathodic electrodeposition of ceramic and organoceramic materials. Fundamental aspects. Adv Colloid Interface Sci 97: 279-317.

21. Neirinck B, Fransaer J, Vleugels J, Van der Biest OO (2009) Aqueous Electrophoretic Deposition at High Electric Fields. Key Eng Mater 412: 33-38.

22. Thomas BJC, Boccaccini AR, Shaffer MSP (2005) Multi-walled carbon nanotube coatings using electrophoretic deposition (EPD). J Am Ceram Soc 88: 980-982.

23. Javidi M, Javadpour S, Bahrololoom ME, Ma J (2008) Electrophoretic deposition of natural hydroxyapatite on medical grade $316 \mathrm{~L}$ stainless steel. Mater Sci Eng 28: $1509-1515$.

24. Ma J, Wang C, Peng KW (2003) Electrophoretic deposition of porous hydroxyapatite scaffold. Biomaterials 24: 3505-3510.

25. Kaya C (2008) Electrophoretic deposition of carbon nanotube-rein forced hydroxyapatite bioactive layers on Ti-6Al-4V alloys for biomedical applications. Ceram Int 34: 1843-1847

26. Franks W, Schenker I, Schmutz P, Hierlemann A (2005) Impedance characterization and modeling of electrodes for biomedical applications. IEEE Trans Biomed Eng 52: 1295-1302. 